\title{
ESTADO, USO DO TERRITÓRIO E PROCESSO DE DEMOCRATIZAÇÃO NA AMÉRICA LATINA
}

\author{
Edilson Luis de Oliveira \\ Doutor em Geografia pela Universidade de São Paulo. Professor do Departamento de \\ Geociências da Universidade Estadual de Londrina. \\ E-mail: edilson@uel.br
}

\begin{abstract}
RESUMO
Este artigo pretende discutir os parâmetros que permitam analisar as relações entre estado e democracia na América Latina, a partir da dinâmica territorial. Pretende verificar a forma como as crescentes desigualdades sociais, a fragmentação e extroversão do território na América Latina colocam em risco a consolidação democrática na região.

Palavras-Chave: Democracia. América Latina.
\end{abstract}

\begin{abstract}
This article is an attempt to discuss the parameters for the analysis of relations between the state and democracy in Latin America within the territorial dynamics. It intends to verify how increased social inequalities, fragmentation and extroversion of the Latin American territory pose at risk the regional democratic consolidation.

Key words: Democracy. Latin American.
\end{abstract}

A democracia na América Latina é um sistema que deve ser pensado à luz de suas características peculiares. É sabido que, sobre o conceito de democracia, não há consenso entre os estudiosos, especialmente quando a discussão diz respeito ao contexto de países subdesenvolvidos (SANTOS, 2001).

Mas, se há controvérsias em torno do conceito, é certo que, o processo de democratização na América Latina se reveste de grande complexidade. Neste trabalho pretendo abordar a questão a partir de algumas considerações sobre as relações entre o Estado e o uso e ordenamento do território no contexto das recentes reformas neoliberais.

Dada à complexidade da questão, é necessário estabelecer alguns parâmetros que permitam analisar essas relações, levando em conta o contexto histórico concreto em que se realizam. Refiro-me, por exemplo, às relações complexas entre Estado, uso e ordenamento do território e política econômica, que torna particulares os projetos nacionais e os regimes políticos latinoamericanos. Outro aspecto a considerar é o que se refere às crises de legitimidade que governos democraticamente eleitos experimentam quando, uma vez no exercício do poder, sucumbem aos imperativos do neoliberalismo, em nome de uma aparente governabilidade, em que as forças democráticas são deslocadas 
pelas de um mercado global, controlado a partir de centros internacionais.

Nos países desenvolvidos os sistemas democráticos enfrentam problemas como: a indiferença, a apatia política dos cidadãos, a descrença no processo eleitoral e na representação político partidária e o ressurgimento e fortalecimento de grupos fascistas.

Na América Latina, há processos específicos como a ampliação das desigualdades sociais, da pobreza e da indigência que abrem brechas perigosas para que, caudilhos e populistas aflorem na cena política. Por fim é preciso enfatizar que as crescentes desigualdades sociais, a fragmentação e atual forma de extroversão do território na América Latina constituem uma "situação de risco permanente de involução democrática” (AINSA, 2004).

É a partir desse contexto que as transformações recentes na dinâmica territorial dos países latino-americanos ganham relevância.

\section{Algumas questões conceituais.}

O território é um daqueles conceitos que, na linguagem cotidiana, adquire certa polissemia. Não é diferente no contexto acadêmico, pois termos como territorialização/desterrritorialização, por exemplo, têm sido empregados por autores das ciências humanas para identificar processos de natureza diversa. Para evitar situações desse tipo, tomo o conceito de território num sentido bastante restrito, isto é, o de espaço territorial de um Estado Moderno.

É com base no par - Estado e Território - que pretendo indicar, as relações entre transformações importantes no uso e ordenação dos territórios em alguns países latino-americanos ${ }^{1}$ e o contexto das reformas neoliberais. Contudo, não se trata, apenas, do território em si. Segundo Milton Santos (2001, p.247), quando se pretende considerar o espaço geográfico como tema das ciências sociais, ou seja, como questão histórica, a categoria de análise, é o território utilizado, pois assim se pode considerar adequadamente "a interdependência e a inseparabilidade que existe entre a materialidade, que inclui a natureza, e seu uso, que inclui a ação humana, isto é o trabalho e a política.”.

Outra questão conceitual importante é a que diz respeito à interpretação do papel e da natureza do Estado nos países latino-americanos. O tema gerou intenso e extenso debate, desde os anos 1960. Cabe, portanto, estabelecer alguns marcos em torno dos quais considero o problema.

Quanto ao Estado nos países subdesenvolvidos, considero como parâmetros para análise: a definição de sua natureza de classe a partir da

\footnotetext{
1 Buscarei exemplificar alguns processos a partir das realidades específicas dos três maiores e economicamente mais importantes países da América Latina - Argentina Brasil e México.
} 
economia mundial constituída (MATHIAS; SALAMA, 1983), sua autonomia relativa frente aos países desenvolvidos, frente às respectivas formações nacionais e à própria economia mundial constituída, permitindo, por exemplo, um grau mais elevado de soberania, no período de 1930 a 1980, conforme a hipótese sustentada por Wilson Cano (2000).

A constituição dos territórios e dos Estados na América Latina teve relações diretas com seu passado colonial. Para Argentina, Brasil e México, os três países com maior extensão territorial da América Latina, a definiçãa de certas centralidades em seus respectivos territórios, a distribuição da população, especialmente a de origem européia, e dos núcleos urbanos mais antigos reflete claramente a herança colonial. Sobre essa herança, no âmbito da ação dos Estados nacionais, constituíram-se distintos meios geográficos, como o meio técnico e o atual meio técnico-científico-informacional (SANTOS; SILVEIRA, 2001) que, considerados à escala da formação socioespacial, estão relacionados diretamente à intervenção do Estado no bojo de projetos nacionais pautados na constituição do mercado interno e na integração do território e em uma inserção menos dependente da região na divisão internacional do trabalho, resultando em diferentes formas de valorização e gestão do território, mais ou menos soberanas, o que não excluiu sua crescente internacionalização.

A soberania, entendida aqui como autonomia para realizar um projeto nacional de desenvolvimento no qual se entrelaçam, políticas econômicas e políticas de ordenamento e gestão do território, é uma das variáveis que permite identificar e estabelecer as diferenças entre os diversos regimes políticos nos quais o Estado se realiza, e estabelecer bases para uma periodização. Em um trabalho recente e de grande fôlego, Wilson Cano (2000) apresenta e discute a possível perda de soberania que os países da América Latina sofreram em relação à capacidade de gerir suas políticas econômicas. $\mathrm{O}$ autor indica que o início desse processo de redução da soberania estaria na crise dos anos 1980, a década perdida. Os processos de renegociação das dívidas externas, as gradativas aberturas dos mercados internos para as importações, a estatização das dívidas em moeda estrangeira do setor privado, especialmente a dos bancos, foram verdadeiras pontas de lança para a captura do Estado na América Latina.

Com os processos de democratização em diversos países, a conjuntura favoreceu e acabou funcionando como trampolim para que tecnocratas, imbuídos da ideologia neoliberal e partidos de diversas orientações ideológicas, formassem uma espécie de coalização pelas reformas, pregadas pelos organismos internacionais. Via de regra, o acesso dessas coalizões ao poder se deu, a partir do início dos anos 1990. 
No México o processo iniciou-se antes da assinatura do Tratado de Livre Comércio com os EUA, no mandato de Miguel de La Madrid (19821988), ou mais exatamente a partir de 1987, quando o governo propõe o Pacto de Solidariedade Econômica (PSE). Esse pacto foi um acordo entre governo, empresários e trabalhadores, que consistia em: controlar temporariamente preços e salários, realinhar preços, cortes no crédito e redução da quantidade de moeda em circulação, abertura comercial e privatizações. (CANO, 2000, p. 419).

Wilson Cano (2000, p.13), insiste que, ao propor os anos entre 1929 e 1979, como um período que "[...] constitui, para uma parte dos países da América Latina, um longo e excepcional grau de soberania no exercício e no manejo da política econômica de desenvolvimento", não se trata de pensar que o imperialismo tenha dado trégua durante todo o período ou que nos tivéssemos tornado independentes. Essas ressalvas do autor vão de encontro às afirmações de Mathias e Salama acerca da autonomia relativa dos regimes políticos que dão existência concreta ao Estado nos países subdesenvolvidos.

A autonomia relativa do Estado passa por uma determinação de sua natureza de classe original. Essa provém da economia mundial constituída. O Estado é assim o lugar onde se cristaliza a necessidade de reproduzir o capital em escala internacional, bem como o elemento necessário a essa reprodução. Essa particularidade na determinação de classe do Estado tem uma importante conseqüência. A autonomia relativa dos regimes politicos - formas de existência do estado - concebe-se num duplo nível: sua nação (sua formação social) e as nações do centro (seus regimes políticos). Por isso, a política econômica dos governos é, ao mesmo tempo, submetida e independente. Ela reflete o peso da divisão internacional do trabalho que tem de sofrer. E expressa a tentativa de se libertar de tal peso. (MATHIAS, 1983. p. 78).

Os autores explicam que essa seria uma das razões pelas quais a intervenção do Estado na acumulação de capital nos países subdesenvolvidos, assume proporções bem maiores do que nos países desenvolvidos. O Estado, nos países subdesenvolvidos, se mostra assim muito mais presente na produção de relações de produção capitalistas, ao investir pesadamente em setores produtivos como o energético e o de infraestrutura.

A riqueza da interpretação que os argumentos de Mathias e Salama proporcionam se expressa, por exemplo, na possibilidade de especificar o modo como a luta de classes exerce um papel decisivo na definição das estratégias de ação do Estado. Assim, compreende-se como no Brasil, por exemplo, regimes políticos, a exemplo do Populismo dos anos 1950, que se definiu por um pacto de poder que reunia de um lado a elite agrária e a jovem burguesia industrializante e de outro, essa mesma jovem burguesia e o 
operariado, puderam lograr a construção e efetivação, ainda que parcial, de um projeto nacional desenvolvimentista, aproveitando a conjuntura internacional favorável.

Os argumentos permitem ainda trazer para um plano de centralidade o debate sobre a ordenação do território e sua relação dialética com a política e a economia propriamente ditas.

Não é apenas pelo que particulariza o Estado nos países subdesenvolvidos que o argumento dos autores é importante. Sua importância também se revela pelo que o Estado em questão deixa de fazer, como a maior atenção e participação no orçamento público de tudo que se refere à reprodução da força de trabalho, fato que, segundo os autores, caracteriza os regimes políticos dos países desenvolvidos.

Essa argumentação permite uma reflexão sobre as possibilidades que a democracia, ainda que formal, representativa e limitada, permite à Sociedade Civil, na medida em que aumenta a porosidade do Estado às suas reivindicações, incluindo as de ordem territorial. Exemplificam essa possibilidade as ações de planejamento regional da União Européia e os famosos subsídios aos camponeses, no âmbito de sua Política Agrícola Comum (PAC), entendidas e consideradas, nesse caso, como tentativas de minimizar os desdobramentos territoriais próprios da dinâmica do mercado e da acumulação de capital e de busca por um ordenamento territorial socialmente mais equilibrado.

Da mesma forma, a presença de regimes autoritários como os que tivemos em diversos momentos na América Latina, apontam para a importância dos vínculos entre política econômica, território e regime político. As lutas dos movimentos sociais dos anos 1980 pela democratização na Argentina e no Brasil indicaram claramente o peso desses vínculos. Dentre os alvos das reivindicações estava justamente um redirecionamento dos orçamentos públicos, de maneira a gerar intervenções estatais e políticas públicas que minimizassem os efeitos perversos da ausência do Estado, no que diz respeito à reprodução da força de trabalho.

Diversos movimentos de então se definiam como contra a carestia, "panelaço", pela construção de creches, escolas, saneamento básico, iluminação pública e asfalto e expressavam as carências de países com intensa e caótica urbanização, bem como as possibilidades de organização, postas por ações como as comunidades eclesiais de base.

No Brasil, o caráter local e localizado desses movimentos fundiu-se, misturou-se com questões relativas à escala do território nacional, como as eleições diretas, uma nova constituição, a consolidação de direitos civis, etc. Ao mesmo tempo a política econômica e a conjuntura internacional pesavam 
sobre as possibilidades da política econômica, de um outro projeto nacional mais eqüitativo e democrático e de um ordenamento territorial correlato. A estagnação da economia, a inflação acelerada, a crise da dívida externa comprometeram os gastos sociais, produziram arrocho salarial e desemprego, trazendo dificuldades para os movimentos sociais, particularmente a organização dos trabalhadores e sua luta contra os baixos salários.

Evidenciava-se assim a espaço-temporalidade da cidadania, como dimensão ontológica dos movimentos sociais ${ }^{2}$ e, portanto, ou dito de outro modo, o caráter territorial da ação política no contexto do Estado Moderno.

A chamada "convergência perversa" a que se refere Evelina Dagnino (2002), indicando a coincidência entre ciclos de democratização e reformas neoliberais, tem produzido impactos múltiplos e contraditórios sobre a esfera pública, em boa parte dos países latino-americanos, na qual atuam os movimentos sociais. Há, até certo ponto, uma pluralização da sociedade que acompanha as reformas neoliberais e a nova inserção da América Latina na divisão internacional do trabalho, mas também há uma intensa fragmentação dos espaços públicos que acompanha a intensificação do processo de urbanização que se estende ao campo, e dos conflitos nas áreas periféricas das grandes cidades com o aumento da criminalidade e violência, ou seja, uma fragmentação dos espaços públicos que é correlata da fragmentação do território em suas diversas escalas.

Cabe nesse momento colocar em evidência a ordenação territorial presente, em que os movimentos sociais mencionados despontaram e que pautou os projetos de desenvolvimento latino-americanos, durante o período em que vigorou um maior grau de soberania como defende Wilson Cano, como forma de enfatizar as transformações do atual período histórico e suas implicações para o processo de democratização das sociedades latino-americanas.

\section{Estado e território na América Latina antes das reformas neoliberais}

A constituição do meio técnico na América Latina se deu de forma mais ou menos semelhante nos grandes países da região, pois foi comandada por sua variável determinante, mas não dominante, porque inicialmente estava situada fora do continente: a indústria. Para além das semelhanças na estrutura industrial, produzidas pelo processo de substituição de importações e pela

\footnotetext{
2 "Entendo que o conceito de cidadania possui uma dimensão espacial ontológica fundadora,além de ser uma prática social constituída historicamente em algumas sociedades, que regula as relações sociais; por isso ganha ou não existência em determinadas formações sociais e tem se transformado ao longo do tempo e dos modos de produção.[...] As noções e territórios atrelados aos conceitos de cidadania possibilitam a visualização dos contornos de sua especificidade em cada sociedade, ou seja, permitem verificar suas diferenças e origens sociais em cada momento histórico. (KATUTA, 2005, p. 127, 129.)
} 
ação do Estado intervencionista, há, em relação ao ordenamento territorial, alguns aspectos importantes a ressaltar. Um deles é que, no âmbito do ordenamento territorial fundado no mercado interno e na integração territorial, houve melhores possibilidades de melhoria das condições de vida de uma grande parte da população, inclusive com distribuição de renda menos desequilibrada e porcentagens de pobres e indigentes menores que as atuais ${ }^{3}$, isto é, que os índices posteriores às reformas neoliberais.

Em relação ao ordenamento territorial, um primeiro exemplo pode ser pensado a partir da intensidade do processo de urbanização e de sua concentração espacial. A presença da chamada "macrocefalia urbana" expressa no gigantismo de suas metrópoles nacionais frente ao resto do território é sem dúvida um indicador da aproximação que se pode traçar entre Argentina, Brasil e México que representam, em conjunto, a maior parte da população e da riqueza latino-americanas. Procederei então a uma breve descrição, de modo a traçar algumas características do uso e da ordenação territorial na Argentina e no México ${ }^{4}$, antes das reformas neoliberais dos anos 1990.

Para a Argentina, por exemplo, Segundo Maria Laura Silveira (2005), em meados do século XIX, a burguesia agrário-exportadora já havia consolidado a participação do país na divisão Internacional do trabalho, associada à exportação de carne, cereais, leite e derivados a partir da região de Buenos Aires e dos pampas. Diversas ações convergiram para dotar essas regiões com importantes sistemas de engenharia: porto, ferrovia e frigoríficos mecanizados traduzem a modernização do território e autorizam novas formas de trabalho e novos ritmos. Essas ações foram completadas e se combinaram com os investimentos de capitais britânicos e a refrigeração nos barcos a vapor, que ampliou as possibilidades de exportação de produtos perecíveis.

A circulação dos excedentes acumulados com a exportação permitiu novas formas de consumo e acentuou, mais cedo do que em outras nações do continente, a urbanização concentrada. Não se pode esquecer da imigração cujo papel, segundo a autora, deve ser ressaltado "pela repercussão na

\footnotetext{
${ }^{3}$ Entre 1999 y 2002, el proceso de superación de la pobreza no mostró avances significativos. De hecho, en ese período la tasa de pobreza aumentó 0,2 puntos porcentuales, mientras la indigencia registraba un alza de 0,9 puntos. En términos absolutos, el número de pobres se vio incrementado en cerca de 10 millones de personas, de las cuales 8 millones correspondieron a personas en condiciones de extrema pobreza. La comparación de las cifras del 2002 y de 1990 permite constatar una disminución de la incidência de la pobreza, del $48,3 \%$ al $44,0 \%$ y de la indigencia, del $22,5 \%$ al $19,4 \%$. Esta reducción en términos porcentuales no fue suficiente para compensar el crecimiento de la población, de manera que en términos absolutos en el 2002 había 21 millones más de personas pobres que en 1990, de los cuales 4 millones eran indigentes.

${ }^{4}$ Seguindo essa linha teórica, uma análise bastante completa a respeito do território brasileiro está disponível no trabalho de Milton Santos e Maria Laura Silveira (2001), intitulado: Brasil território e sociedade no início do século XXI, já citado neste artigo. Para comparações em relação ao um período mais amplo, envolvendo as décadas de 1970 e 1980, ver o trabalho de Cano (2000).
} 
constituição de uma população economicamente ativa e, ao mesmo tempo, desejosa de consumos materiais e políticos." (SILVEIRA, 2005, p. 182).

Com as Guerras mundiais e a substituição de importações, a industrialização, agora presente no território argentino, geraria novos nexos, novas normas e desdobramentos políticos ${ }^{5}$ e, sobretudo, novos ritmos para o processo de urbanização.

Com forte participação do Estado, o território será reequipado, e a circulação redefinida, com a criação de uma malha rodoviária mais densa, e convergente para a região de Buenos Aires, como as ferrovias.

Empresas estatais foram constituídas com a incumbência de criar o arcabouço produtivo e regulatório necessário, quando o capital privado estivesse ausente. Dos anos 1960 em diante, o processo conhece certa inflexão, vejamos:

Uma fase de internacionalização atingiu, a partir da década de 1960, todas as esferas da vida social. A busca da modernidade tornou-se um imperativo e o uso do território transformou-se com a chegada de capitais americanos na agricultura, na indústria, no comércio e nos serviços, levando a quimicização do campo, da alimentação, da saúde e da indústria com o concurso de abundantes capitais financeiros que, sobejando no sistema, escolheram enraizar-se em um território bastante produtivo. Um sistema técnico baseado no uso intensivo de energia, que acabou por atrelar o país à instalação de grandes hidrelétricas com financiamento estrangeiro e, ainda mais, a uma premente exploração petrolífera perfazia-se com uma rede de circulação fundada na unificação do território pelas rodovias que abrigariam importantes fluxos de passageiros e cargas, imprimindo uma nova aceleração ao território.

A artificialização do meio geográfico, onde a técnica tornava-se um conteúdo crescente e passava a autorizar novos comportamentos, completou a integração do território ao mercado. Todavia, o processo se fez ao preço de um alto endividamento externo que, a partir de então, despontou claramente como o eixo das políticas econômicas da nação. (SILVEIRA, 2005, p. 184)

O trecho citado indica claramente duas ligações importantes do ponto de vista da presente reflexão. A primeira é que, com a nova fase do meio técnico, marcada pela constituição de novos sistemas de engenharia, após os anos 1960, são estabelecidas as condições para um elevado grau de

\footnotetext{
${ }^{5}$ Ao referir-se as novas demandas por força de trabalho geradas pela industrialização e à sua concentração na região de Buenos Aires, Maria Laura Silveira (2005) assinala que: "Essa massa será protagonista de um processo de reivindicação cuja manifestação mais clara foi uma época interrupta de governos de inspiração nacionalista." Entendo que a concentração dos trabalhadores em grandes centro urbanos é um aspecto do ordenamento territorial provocado pela nova variável, a industria criada pela substituição de importações, com papel motor em termos políticos, influenciando, como assinala a autora, na configuração do regime político.
} 
internacionalização dos atores que usam o território. Por outro lado, produz-se um ordenamento territorial predominantemente centrado no mercado interno.

A segunda ligação consiste no fato de que, a nova configuração do território produziu impactos consideráveis na política econômica do país, com implicações para o processo de captura do Estado e redução da soberania explicitado por Wilson Cano (2000), especialmente o forte endividamento externo.

No caso do México, o processo de estruturação do território possui especificidades marcantes quando comparado a outros de grande extensão, como Brasil e Argentina, particularmente, quanto ao meio rural e aos desdobramentos da Revolução de 1910, como a longa permanência de regimes democráticos marcados pela hegemonia do Partido Revolucionário Institucional (PRI). As semelhanças começam a aparecer a partir dos anos 1930, como relata Daniel Nicolas-Hiernaux (2005, p.27):

Os esforços para impulsionar o desenvolvimento nacional empreendidos pelos governos pós-revolucionários, especialmente a partir de 1934 (data da posse do general Lázaro Cárdenas como presidente da República), conduziram à crescente centralização do país. De um lado, a política foi orientada para uma centralização considerável, tanto no partido oficial quanto nas estruturas sindicais, entre outras. De outro, construiu-se a andaimaria institucional que propiciaria um crescimento considerável e uma transformação sem precedentes do país, para alcançar, uma espécie de "milagre mexicano": cabe destacar que, desde antes do início da fase de crescimento acelerado, o México já contava com todas as instituições de desnvolvimento - os bancos públicos, as empresas paraestatais e o sistema legal que garantiriam a regulação necessária de um futuro modo de desenvolvimento que podemos qualificar de "fordismo periférico estatal".

O autor assinala ainda que o modo de desenvolvimento apontado na citação era de base urbano-industrial, e tal como no Brasil ou na Argentina produziu uma enorme macrocefalia urbana, traduzida na aglomeração gigantesca da cidade do México, localização central de um sólido mercado interno. A urbanização intensa alimentada por migrantes rurais permitira a formação de outros grandes centros como Guadalajara na porção oeste do país e Monterrey na parte nordeste. As semelhanças com o território argentino e brasileiro se traduzem ainda pelos desequilíbrios regionais, caracterizados pela enorme concentração da Cidade do México, para onde migrantes eram atraídos pelas possibilidades de melhores condições de vida, em contraste com regiões inteiras submetidas à estagnação por não estarem integradas ao tipo de modernização praticado. Daniel Nicolas-Hiernaux $(2005$, p.26) esclarece: 
O tema da concentração é, talvez, o mais ressaltado pelos analistas do território nacional nesse período, de par com a dispersão da população rural em uma infinidade de pequenas localidades. Contudo, é possível analisá-lo de forma diferente: cabe sublinhar que a Cidade do México foi o destino prioritário dos fluxos migratórios do sul do país, particularmente das zonas camponesas e indígenas, que se integraram paulatinamente a um modelo de inclusão no sistema econômico e político mexicano, o que deixou marcas profundas de melhoria em todos os campos, graças a uma política social que, embora incompleta, não deixou de ser positiva.

O autor também ressalta os efeitos negativos da modernização e industrialização do país, principalmente a partir da Segunda Grande Guerra, destacando os desequilíbrios regionais, a exemplo da região Sul, incapacitada de se integrar economicamente à modernização e ao padrão fordista de crescimento, e os grandes contingentes da população das grandes metrópoles desempregados ou não integrados ao mercado formal de trabalho.

A ampliação da exclusão com as dificuldades enfrentadas pelo prosseguimento do projeto industrializante trouxeram, no âmbito político, certas dificuldades para a legitimação democrática dos governos do PRI, reduzindo paulatinamente sua maioria no parlamento. Uma segunda conseqüência foi o recrudescimento do processo de endividamento do país. As dificuldades mencionadas se relacionam à implantação de um setor de bens de capital correlato da implantação da indústria petroquímica, ao custo financeiro de equipar o território com ferrovias, estradas, portos e aeroportos capazes de atender a expansão das "maquiladoras ${ }^{6}$ ", algumas delas tornando-se de segunda e terceira geração, isto é, mais intensivas em capital e não em trabalho, produtoras de maior valor agregado e com mais efeitos multiplicadores em termos locais e regionais e ao setor automobilístico - montadoras e auto-peças.

Ao longo dos anos 1970, haverá um esforço para ampliar a participação do capital estrangeiro como forma de superar os pontos de estrangulamento da economia e também, gerar pólos de desenvolvimento regional no sul do país ${ }^{7}$. Diferentemente de Argentina e Brasil, o México contará com a renda petrolífera, para auxiliá-lo no enfrentamento das questões financeiras,

\footnotetext{
${ }^{6}$ Empresas sediadas especialmente na região norte do México que, de forma semelhante ao que ocorre na Zona Franca de Manaus, recebem componentes importados e isentos de impostos para montar equipamentos, máquinas ou outras mercadorias que, na sua maioria, serão remetidas para fora do país. Em resumo são indústrias que tem como base a exploração da força de trabalho de baixa remuneração.

${ }^{7}$ No setor de bens intermediários o país buscou investimentos para produção de tubos sem costura e abriu suas fronteiras para que cadeias internacionais de hotéis criassem os pólos turísticos de Cancum e Ixtapa.
} 
calcanhar de Aquiles dos projetos de desenvolvimento latino-americanos, o que, no entanto, não foi suficiente para evitar a estatização de bancos quebrados e passagem para o Governo, de dívidas de empresas privadas, contraídas em moeda estrangeira.

Com a queda nos preços internacionais do petróleo a partir de 1981, o início do mandato de Miguel da La Madrid (1982 -1988), marca o início das reformas liberalizantes naquele país. De imediato, organismos internacionais como o FMI, propuseram e foram atendidos em seu receituário básico: redução do gasto público, congelamento de salários, reestruturação da dívida pública. Repetia-se o abortamento de projetos nacionais de desenvolvimento, redução da soberania e captura do Estado pela via financeira que se abateu sobre Argentina e Brasil. Antes mesmo do que os outros países citados, o México praticou uma abertura unilateral de suas fronteiras reduzindo drasticamente tarifas sobre diversas importações. Mais uma vez passemos a palavra a Daniel Nicalás-Hiernaux (2005, p.32):

O efeito econômico foi, em primeiro lugar, o empobrecimento da população, amplamente documentado por numerosos autores.[...]

O que temos de mais importante a assinalar para o propósito desse trabalho é o efeito territorial dessa abertura: enquanto a proteção e a substituição de importações favoreciam um modelo de concentração e centralização em torno à Cidade do México, a abertura iria golpear prioritariamente aqueles centros de produção industrial de velho tipo, onde era mais forte a indústria tradicional. As grandes metrópoles, e particularmente a Cidade do México, epicentro industrial do país, foram as mais afetadas.

Em resumo, apesar de todas as ressalvas que se deve fazer ao tipo de ordenamento e uso do território que se configurou na Américas Latina até o início dos anos 1980, quando comparados com a dinâmica atual, é preciso ressaltar alguns aspectos que entendo como relevantes para compreensão da complexidade do processo de democratização.

O primeiro deles é o aumento em termos absolutos do número de pobres e indigentes, juntamente com a ampliação das desigualdades sociais na região, como revela o relatório da CEPAL de 2004.

O segundo é que, apesar de todo contexto autoritário, os projetos nacionais de desenvolvimento e a constituição de um meio técnico capaz de constituir um mercado interno, permitiram a esperança de que, em um contexto democrático, uma maior participação da sociedade Civil nas decisões permitisse alcançar alguns objetivos na direção da superação da dependência, dos graves problemas sociais, da desigualdade social, do controle da degradação ambiental, entre outros. 
O terceiro é que, apesar do elevado grau de internacionalização da economia, as possibilidades de uso do território se mostravam mais plásticas frente ao conjunto de atores que ele reúne. Refiro-me, por exemplo, a pequenas e médias empresas em relação aos diversos fluxos, como os que são possíveis a partir das infraestruturas de transporte e do conjunto de normas que interfere no setor, como no caso dos pedágios implantados em certos trechos de rodovias, que oneram pesadamente essas empresas.

\section{Estado e território na América Latina após as reformas neoliberais.}

A partir dos anos 1990, as mudanças políticas que definiram o processo de democratização se fizeram acompanhar das chamadas reformas neoliberais: abertura comercial e financeira reduzindo barreiras legais e tarifárias para a circulação de mercadorias e capitais, intensa privatização de patrimônio público, desregulamentação e flexibilização das legislações trabalhistas, entre outras.

Esse conjunto de reformas atingiu com mais ou menos intensidade os países da região. Da mesma forma, os usos e os novos sistemas de engenharia que desde os anos 1970 vinham sendo implantados na região, foram redefinidos e integrados a diferentes tipos de redes e circuitos espaciais de produção. (SANTOS; SILVEIRA, 2001). Dessa forma, constituiu-se um novo meio geográfico na região, o chamado meio técnico-científico informacional, caracterizado pela informação como variável determinante.

No México a abertura da economia e as privatizações produziram importantes e rápidas transformações no território. De forma resumida NicolasHiernaux (2005, p.40-43) indica que, a partir de meados dos anos 1980, a região norte do México passou por grandes transformações, com a ampliação significativa das maquiladoras que passaram a representar parte expressiva das exportações não-petrolíferas mexicanas. ${ }^{8}$

A Cidade do México, que concentra a maior parte da atividade econômica do país, conheceu uma profunda refuncionalização com a chegadade sedes de sociais de grandes empresas multinacionais, internacionalização de sua arquitetura por meio de grandes projetos imobiliários. Quanto ao sul do país o autor faz uma interessante observação:

Pode-se, todavia, afirmar com toda segurança que a globalização atingiu todo o território mexicano: as cidades do norte e certos territórios produtivos e não urbanos (agricultura de exportação) integraram-se decididamente ao processo globalizador; outros territórios conheceram uma versão negativa desse processo ao

\footnotetext{
${ }^{8}$ Segundo Cano (2000, p. 424), no final dos anos 1980 , as maquiladoras responderam por $73 \%$ das exportações não petroliferas do México.
} 
ver desintegradas suas economias locais, ou seja, ao tornarem-se "territórios que perdem".

Embora possa parecer paradoxal, resulta que o sul também se globalizou, não por integração econômica, mas pela divulgação mundial de suas carências, levadas acabo inicialmente pelos zapatistas [...] (NICOLAS-HIERNAUX, 2005, p. 43).

O sul do país tornou-se explosivo no início da década de 1990, quando a administração Salinas de Gortari (1988-1994), reformou a Constituição e modificou a lei agrária, possibilitando a privatização dos ejidos e propriedades comunais e ampliando o mercado capitalista de terras. Essas alterações, aliadas aos problemas crescentes de desigualdade social e desestruturação das atividades tradicionais da região serviram de estopim para o movimento Zapatista. (CANO, 2000, p. 435).

Em conjunto, as transformações impostas ao território mexicano nesse novo momento revelam claramente uma maior fragmentação, dialeticamente relacionada à ampliação das articulações e fluxos com o exterior, especialmente com os EUA, após a assinatura do Tratado de Livre Comércio. A enorme redução da presença do Estado na economia e no planejamento da ordenação do território se fez simultaneamente à maior participação de capitais estrangeiros nessa tarefa. Ntre os alvos da privatização na região se destacam os setores de produção e distribuição de energia elétrica, petróleo e gás, telecomunicações, bancos e siderurgia.

Segundo Maria Laura Silveira (2005, p.188), na vizinha Argentina uma onda de modernização favoreceu, sob o regime de concessões, um novo espaço de fluxos. Pequenos e médios aeroportos, novos e antigos, remodelados pela informática e telecomunicações se juntaram aos aeroportos metropolitanos abrigando terminais exclusivos para empresas. Portos e rodovias privatizados são modernizados e a rede telefônica se expande. Após a privatização, a produção de energia elétrica realizada a partir de diferentes fontes, foi integrada em um único sistema de distribuição e disponibilizada em quase todo o território.

O processo envolve praticamente todos os setores da economia, com destaque para o financeiro que se torna presente, graças à informática e as telecomunicações, em todo o território. As novas técnicas organizadas como grandes sistemas são muito mais rígidas que as anteriores, ou seja, só admitem aquelas ações que estiverem de acordo com normas estritas de funcionamento, são intensivas em capitais e exigentes de conhecimento. Com isso seu uso é, quase sempre, acessível apenas às grandes corporações.

[...] O porto privatizado do Rio Grande do Sul, cuja especialização é a exportação de grãos e calçados e a importação de adubos e outros insumos agrícolas, ganha um novo papel com a construção de um terminal preparado para os novos fluxos de 
autopeças e automóveis vinculados à instalação da General Motors e da Ford no Estado. Como essas empresas recebem peças, mas também e sobretudo veículos acabados de diversos países, seus terminais portuários exigem a construção de pátios de estacionamento adjacentes, que oscilam entre 30 mil e 180 mil metros quadrados. [...] Mas esse alto consumo de superfície aumenta o tamanho dos portos e seus custos e, ao mesmo tempo, os torna monofuncionais. O sistema de engenharia é organizado em função dessas grandes empresas que escolhem localizações de modo a contar com portos quase privativos, ao mesmo tempo que obtêm benefícios fiscais e lucram com o aumento da circulação material e imaterial entre suas filiais mundiais. O custo para o país como um todo grande, mas o benefício é monopolizado por umas poucas empresas. (SANTOS, SILVEIRA, 2001, p. 61).

No trecho acima, duas tendências devem ser destacadas. A primeira é a rigidez que os objetos geográficos, novos e antigos, adquirem em função da constituição de um novo meio geográfico no território brasileiro. Essa rigidez se revela na tendência à monofuncionalidade do porto, pelo seu uso cada vez mais intenso pelas empresas automobilísticas, excluindo assim outras possibilidades. Essa é uma das diferenças marcantes no uso e ordenamento do território com implicações diretas sobre outras esferas da vida social. As redefinições possibilitadas por um sistema de objetos com vocação para uma crescente rigidez, ampliam a exclusão e torna o território menos apto a acolher outros usos.

A segunda é a vinculação de um porto específico aos fluxos de grandes transnacionais, indicando a adaptação dessa importante infraestrutura as necessidades de fluidez das grandes empresas. Essa insaciável necessidade de fluidez, verificada no exemplo citado, decorre dos imperativos do mercado global como a competitividade. Os novos arranjos requerem novas formas de gestão levadas a cabo pelas privatizações, concessões de serviço público, imposição de normas internacionais, entre outras.

No caso brasileiro, grande parte da gestão dessas concessões acontece no âmbito da chamada arena burocrática ${ }^{9}$, isto é, as decisões são tomadas dentro do aparelho de Estado, no âmbito do Executivo, particularmente das agencias burocráticas que são responsáveis pela política específica para o setor considerado. Sobre o funcionamento da arena burocrática, vejamos trecho a seguir:

[...] Ainda que informal, o acesso a essa arena de atores sociais excluídos pelo regime

\footnotetext{
${ }^{9}$ Maria Helena castro Santos (2001) examina o chamado padrão dual de tomada de decisão no Brasil. A autora explica a divisão de tarefas entre o que ela denomina de arena representativa Parlamentos - e a arena burocrática - interna ao Executivo - indicando que há tipos específicos de decisão tomados em cada arena e comparando o atual regime ao período militar.
} 
militar, com destaque para representações dos trabalhadores, é das diferenças que se registram com relação ao regime precedente. Há aí, portanto, um relativo insulamento em relação aos interesses econômicos, políticos e sociais. Relações informais entre os atores estratégicos e os tomadores de decisão são freqüentes e dominantes [...] (SANTOS, 2001, p. 749).

O relativo isolamento que a autora menciona é maior quando as solicitações e pressões partem de grupos populares e não hegemônicos de um modo geral. Por outro, lado os atores estratégicos mencionados, incluem, certamente, os oligopólios nacionais ou estrangeiros.

Essa tendência em relação à forma de administração do processo decisório em um regime democrático é indicativa dos atores que, no presente são responsáveis diretos pelas relações entre Estado e mercado e pela formulação e gestão de políticas territoriais.

As bases normativas da moderna divisão territorial do trabalho renovam as relações entre Estado e mercado, aproximando o pêndulo mais de uma cooperação e menos de uma disputa. Desenham-se pontos e áreas propícios à ação de uma firma global que, agindo de forma independente ou amiúde em parceria com oligopólios nacionais, metamorfoseia os imperativos da sua microeconomia em políticas macroeconômicas da nação [...]

Quando é priorizada uma política setorial dessa natureza, as ações dos ministérios e secretárias nacionais cortam verticalmente as áreas contíguas, e os níveis horizontais de governo, como as províncias e os municípios, são chamados a colaborar, criando densidades técnicas [...]

Quem conduz e legitima o processo é uma neoburocracia, formada de agentes públicos e privados, cuja principal novidade é o domínio ostensivo do conhecimento técnico-científico. É uma racionalização de todas as ordens da vida, mas sobretudo da política[...] (SILVEIRA, 2005, p. 192, 193 e 195).

O trecho acima revela que a subordinação das políticas econômica e de ordenação do território, ao mercado global e sua racionalidade tem implicações para o próprio pacto federativo, na medida em que favorece processos com a guerra fiscal, e gera tensões entre os diferentes entes federativos, sem oferecer, como no passado, um projeto nacional capaz de articular os diversos lugares em torno do mercado interno.

A ausência de debate público sobre essas questões é em parte preenchida por argumentos ditos técnicos, característica marcante da racionalização dos discursos de legitimação dos governos que chegaram ao poder ao longo dos anos 1980 na América Latina. Essa racionalização tem coincidido com os efeitos perversos da extroversão do uso do território, da desnacionalização da economia, do aumento da pobreza, da desigualdade social e da fragmentação do território. 
Para concluir, considerando as observações feitas até aqui, é possível afirmar que, a partir das bases técnicas constituídas no presente ordenamento territorial e da nova regulação exercida pelo Estado, a partir das reformas neoliberais, houve uma clara inflexão na direção de uma maior integração do território e da economia no mercado global em detrimento do mercado interno. Essa mudança implica em uma maior fragmentação do território, uma intensificação das tendências de ampliação da rigidez e da fluidez do território, benéficas às grandes corporações e redutora em relação à possibilidade de um projeto social mais autônomo e mais permeável ao debate político.

Certamente, em tais condições, é possível perceber que, na maioria das vezes, frente à força e intensidade dos processos analisados, a resistência que surge nos lugares encontra dificuldades para ganhar a escala nacional e criar as possibilidades de construir um outro pacto de poder, capaz de redefinir a crescente alienação dos territórios nacionais na América Latina.

\section{REFERÊNCIAS}

AINSA, Fernando. Un desafio impostergable: utopizar la democracia. Cuadernos Americanos, México, v. 1, n. 103, p. 11-33, jan./fev. 2004.

CANO, Wilson. Soberania e política econômica na América Latina. São Paulo: Ed. UNESP, 2000.

DAGNINO, Evelina. Sociedade Civil e Espaços Públicos no Brasil. São Paulo: Paz e Terra, 2002.

KATUTA, Ângela M. A(s) Cidadania(s), os movimentos sociais e as espaço-temporalidades. In: COSTA, Lucia Cortes; SOUZA, Maria Antonia. (Org.). Sociedade e Cidadania: desafios para o século XXI. Ponta Grossa: Ed UEPG, 2005. p. 127-129.)

MATHIAS, Gilberto; SALAMA, Pierre. O estado superdesenvolvido: das Metrópoles ao Terceiro Mundo. São Paulo: Brasiliense, 1983.

NICOLAS-HIERNAUX, Daniel. Globalização e exclusão no México: um enfoque sócio geográfico, In SILVEIRA, Maria Laura (Org.). Continente em chamas: globalização e território na América Latina. Rio de Janeiro: Civilização Brasileira, 2005.

SANTOS, Maria Helena de Castro. Que democracia? Uma visão conceitual desde a perspectiva dos países em desenvolvimento. Dados- Revista de Ciências Sociais, Rio de Janeiro, v. 44, n. 4, p 729-771. 2001.

SANTOS, Milton; SILVEIRA, Maria Laura. Brasil: território e sociedade no início do século XXI. Rio de Janeiro: Record, 2001.

SILVEIRA, Maria Laura. Argentina: do desencantamento da modernidade à força dos lugares. In: SILVEIRA, Maria Laura (Org.) Continente em chamas: globalização e território na América Latina. Rio de Janeiro: Civilização Brasileira, 2005. 